\title{
Tropane and Related Alkaloid Skeletons via a Radical [3+3]- Annulation Process
}

Eloïse Colson, ${ }^{a}$ Julie Andrez, ${ }^{\mathrm{b}}$ Ali Dabbous, ${ }^{\mathrm{b}}$ Fabrice Dénès, ${ }^{a}$ Vincent Maurel, ${ }^{* \mathrm{~b}}$ Jean-Marie Mouesca, ${ }^{* b}$ and Philippe Renaud*a

a) University of Bern, Department of Chemistry, Biochemistry and Pharmaceutical Sciences (DCBP), Freiestrasse 3, CH-3012 Bern, Switzerland

b) Univ. Grenoble Alpes, CEA, CNRS, IRIG , SyMMES, F-38000 Grenoble, France

\section{Abstract}

A mild and simple protocol for the synthesis of 8-azabicyclo[3.2.1]octane and 9azabicyclo[3.3.1]nonane derivatives is described. It provides these valuable bicyclic alkaloid skeletons in good yields and high levels of diastereoselectivity from simple and readily available starting materials using visible-light photoredox catalysis. This unprecedented annulation process takes advantage of the unique reactivity of ethyl 2-(acetoxymethyl)acrylate as a 1,3-bis radical acceptor and of cyclic $\mathrm{N}, \mathrm{N}$-dialkylanilines as radical 1,3-bis radical donors. The success of this process relies on efficient electron transfer processes and highly selective deprotonation of aminium radical cations leading to the key $\alpha$-amino radical intermediates.

\section{Introduction}

Nitrogen-containing moieties are omnipresent in natural products, biologically active compounds and agricultural chemicals. In particular, the 8-azabicyclo[3.2.1]octane and 9-azabicyclo[3.3.1]nonane skeletons constitute the core of many natural tropane ${ }^{1}$ and homotropane alkaloids, ${ }^{2}$ respectively, and analogues presenting a wide range of biological activities. For instance, tropinone, cocaine and scopolamine (Figure 1) are amongst the most popular representative examples of natural alkaloids presenting a 8-azabicyclo[3.2.1]octane (tropane) skeleton as their base structure. Unlike its natural enantiomer, unnatural (-)-ferruginine (Figure 1), is a good agonist for nicotinic acetylcholine receptor (nAchR). The 9-azabicyclo[3.3.1]nonane (homotropane) skeleton can be found in the structure of (-)adaline, and (+)-euphococcinine (Figure 1), ${ }^{2}$ two important defensive alkaloids from, respectively, the European ladybug Adalia bipunctata and the Australian ladybug Cryptolaemis montrouzieri. 

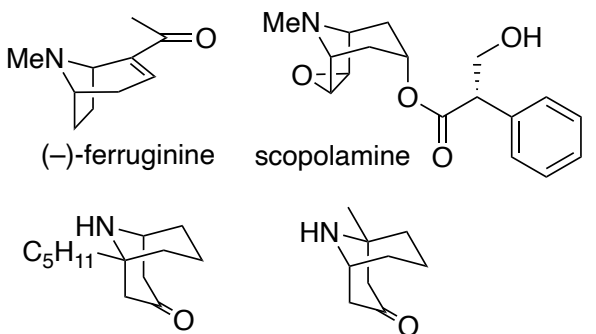

$(-)$-adaline

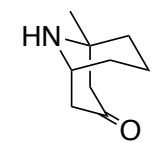

(+)-euphococcinine

\section{Figure 1. Selected examples of tropane and homotropane alkaloids}

Since the report by Robinson of the multicomponent synthesis of tropinone based on a cascade Mannich reaction, ${ }^{3,4}$ access to tropanes and related alkaloids has been the object of intense activity. ${ }^{5}$ Strategies based on ionic reactions, cycloadditions and transition metal mediated processes have been reported. Despite its attractiveness to build cycles, radical processes have only been scarcely used. ${ }^{6}$ The development of a general and flexible access to tropane related heterocycles using a mild radicalbased approach is expected to complement nicely the existing methods. To gain in efficiency, a cascade processes involving consecutive formation of $\mathrm{C}-\mathrm{C}$ bonds is particularly sought. The biosynthesis of tropane alkaloids ${ }^{7}$ as well as Robinson biomimetic synthesis ${ }^{3,4}$ are both based on an ionic [3+3]annulation processes involving 1,3-bis-iminium ions and 1,3-bis-enolates synthons (Scheme 1, A). Inspired by this observation, we hypothesized that a radical version might be possible by using 1,3-bis$\alpha$-amino radical donor and 1,3-bis radical acceptor (Scheme 1, B), radical donor and acceptor being defined and represented according to Curran's proposal in his seminal article on retrosynthetic planning of radical reactions. ${ }^{8}$ To the best of our knowledge, this type of radical [3+3]-annulation has not yet been reported. ${ }^{9-12}$

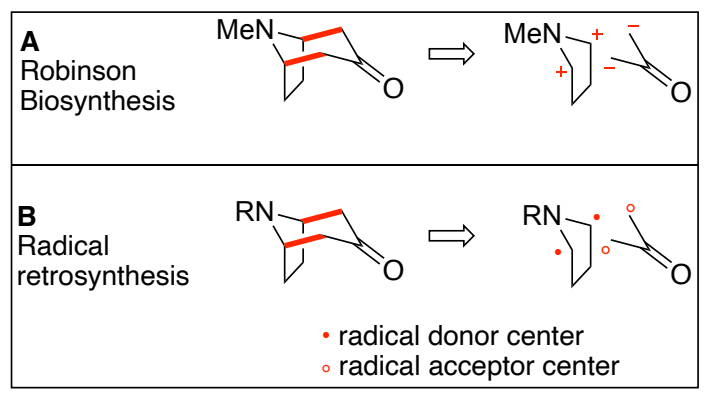

Scheme 1. Retrosynthetic analysis of tropane alkaloids according to their biosynthesis and to Robinson synthesis (A) as a source of inspiration for a radical retrosynthetic analysis (B)

The $\alpha$-functionalization of tertiary amines has attracted much interest in the past and methods involving one- and two-electron oxidation pathway have been reported (Scheme 1). One-electron oxidation of the amine affords a nitrogen-centered radical cation. The oxidation leads to a massive increase of the acidity of the $\alpha-\mathrm{C}-\mathrm{H}$ bond relative to the starting amine. ${ }^{13}$ Rapid deprotonation of the 
radical cation gives the $\alpha$-aminoalkyl radical that can be used for a variety of radical processes, such as for instance addition to alkenes leading to $\mathrm{C}-\mathrm{C}$ bond formation (one-electron pathway). ${ }^{14} \mathrm{O}$ the other hand, the $\alpha$-aminoalkyl radical is more easily oxidized than the starting amine and therefore further oxidation to the corresponding iminium ion can take place (two-electron pathway). ${ }^{15}$ The iminium intermediate can be used for a variety of useful ionic transformations. ${ }^{16,17}$ As a consequence, the use of stoichiometric oxidants to perform radical reaction via the one-electron pathway is very challenging due to rapid overoxidation of the intermediate $\alpha$-aminoalkyl radical to the corresponding iminium ion. ${ }^{18}$

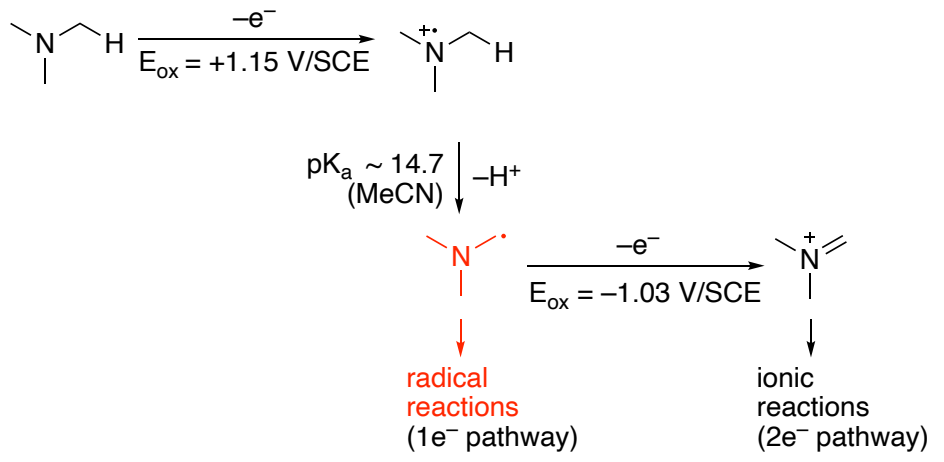

Scheme 2. Oxidation of trimethylamine: one- vs. two-electron pathways

In this context, the single electron oxidation of amines via photoinduced electron transfer has been shown to be a suitable method to suppress this overoxidation. Mariano and co-workers reported in 1992 the photosensitized generation of $\alpha$-aminoalkyl radicals from easily oxidized $\alpha$-silyl amines and their subsequent intra- and intermolecular addition to electron-poor olefins. Interestingly, they reported a 6-endo-trig cyclization process (Scheme 3A). ${ }^{19}$ Pandey took also advantage of the oxidation of a bis- $\alpha$-silylamine to generate an azomethine ylide that can be used in 1,3-dipolar cycloaddition. ${ }^{20}$ Pandey, Reiser and co-workers ${ }^{21}$ and Nishibayashi ${ }^{14,22}$ independently extended this chemistry to photoredox-mediated protocols not only on $\alpha$-silylated amines but also respectively on $\mathrm{N}$-aryltetrahydroisoquinolines ${ }^{21}$ and on cyclic and acyclic amines. Nishibayashi and co-workers reported the formation of bis-alkylated product starting from symmetrical starting materials, demonstrating that the intermediate mono-alkylated product has a similar reactivity as the starting amine under specific reaction conditions (Scheme 3B). ${ }^{22}$ In 2014, MacMillan and co-workers reported the $\alpha$-vinylation of aniline derivatives and $\mathrm{N}$-Boc-protected amino acids using vinyl sulfones as coupling partners (Scheme 3C). ${ }^{23}$ In this case, no bis-vinylation was reported presumably due to the excess of the starting amine used under their conditions. The same year, Li and co-workers reported the first $\alpha$-allylation of $\mathrm{N}$-aryl tertiary amines using an allylic radical trap. ${ }^{24}$ Double addition to the radical trap was observed in one case albeit in very moderate yield (Scheme 3D). In 2020, Ready and co-workers reported a method for 
the regioselective $\alpha$-functionalization of tertiary amines. Interestingly, the initially formed $\alpha$-alkylation product could be further alkylated in a one-pot sequence (Scheme $3 \mathrm{E}) .{ }^{25}$ The second alkylation takes place in a regioselective manner at the aliphatic position over the benzylic position. In one example, they observed the formation of a remarkable [3+3] adduct (Scheme 3E). In this reaction, the initial radical adduct is presumably abstracting a hydrogen from the benzylic position. Reduction of the benzylic radical followed by nucleophilic displacement of the Evans auxiliary account for product formation. All these results incited us to examine the approach described in Scheme $3 \mathrm{~F}$ where $\alpha, \alpha^{\prime}-$ double activation of cyclic tertiary $\mathrm{N}$-arylamines will be used to generate the 1,3-bis radical donors and substituted ester activated allylating agents will be used as a 1,3-bis radical acceptors. The success of this approach will require the ability to meet several challenges such as for instance the control of the regioselectivity of the formation of the second radical and the ability to run a 6-endo-cyclization process leading to a bicyclic framework in competition with intermolecular processes either with the trap or with the monoallylated tertiary amine.
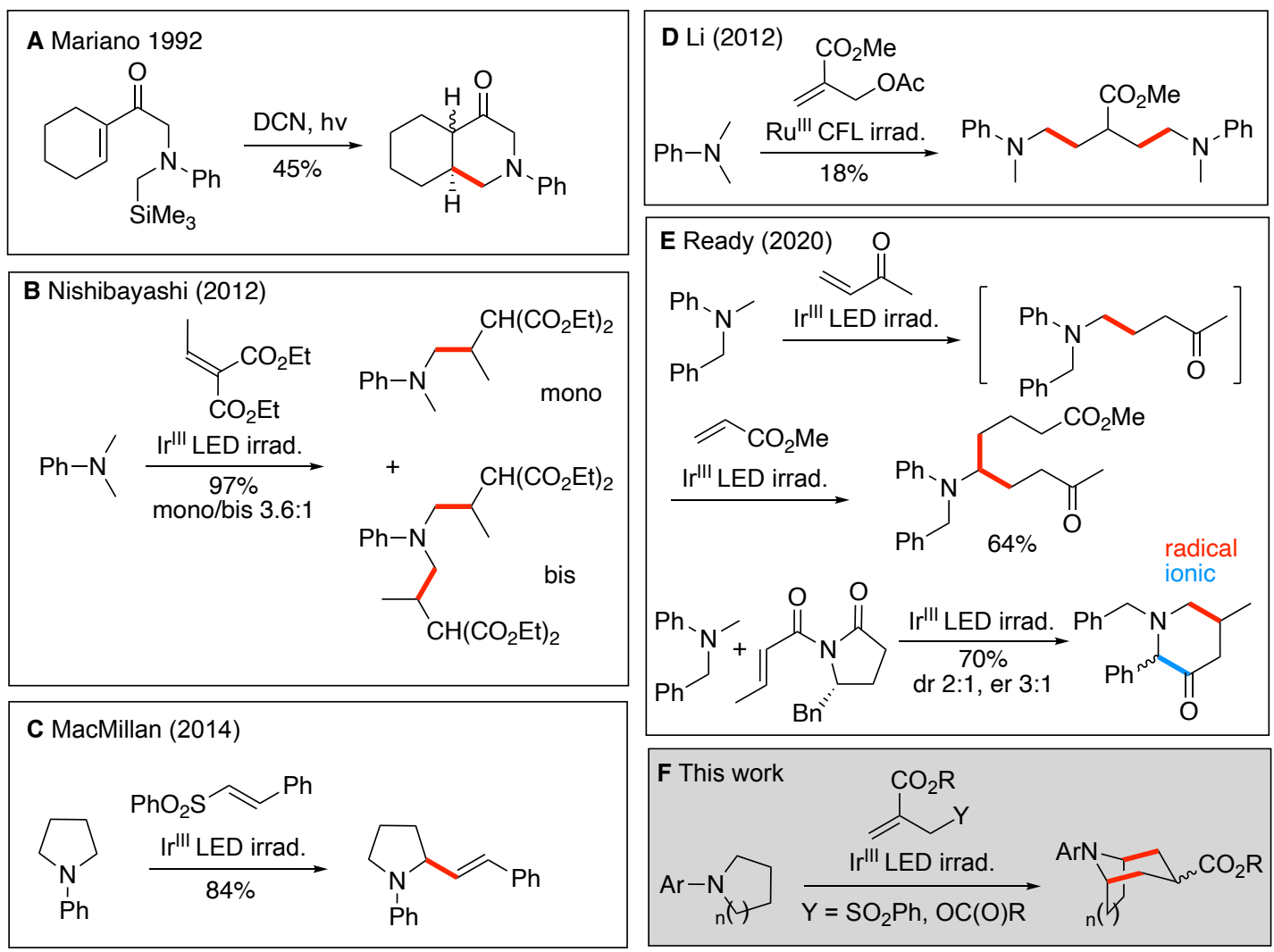

Scheme 3. Photoredox catalyzed $\alpha$-functionalization of tertiary amines. Leading contributions in the field (A-D) and proposed annulation strategy (F). 
Proof of concept and optimization. To prove the validity of the annulation approach, $\mathrm{N}$ phenylpyrrolidine 1a was reacted in 1,2-dichloroethane with a series of allyl radical traps possessing different leaving groups $Y$ in the presence of different catalysts and base additives. The results are collected in Table 1 (more entries are available in the supporting information). Three side products were identified during this optimization phase: the mono-allylated product $\mathbf{2 a}$ (an intermediate in the reaction leading to $\mathbf{3 a}$ ), the $\alpha, \alpha^{\prime}$-bis-allylated product $\mathbf{4 a}$ and the bis-addition product $\mathbf{5} \mathbf{a}$. Since all these side products are difficult to separate from the desired tropane $\mathbf{3 a}$, conditions were sought to minimize their formation. We started the optimization by using ethyl 2-((phenylsulfonyl)methyl)acrylate $(Y=$ $\mathrm{SO}_{2} \mathrm{Ph}, 1.2$ equivalents) as a trap under conditions similar to the one reported in the literature for reactions with vinyl sulfones (see Scheme $2 \mathrm{C}$ ), ${ }^{23}$ i.e. by using $\left[\operatorname{Ir}\left\{\mathrm{dF}\left(\mathrm{CF}_{3}\right) \text { ppy }\right\}_{2}(\mathrm{dtbpy})\right] P F_{6}(\operatorname{Ir}-\mathrm{A})$ as a catalyst, CsOAc (3 equivalents) as a base and irradiating with $390 \mathrm{~nm}$ LEDs in 1,2-dichloroethane (DCE) (Table 1, entry 1). Gratifyingly, the reaction afforded the desired tropane 3a in 45\% yield (all yields determined by ${ }^{1} \mathrm{H}-\mathrm{NMR}$ analysis using an internal standard). Decreasing the base loading to 1.2 equivalents and slightly increasing the amount of the allylsulfone to 1.4 equivalents proved to be beneficial and the product was formed in 65\% yield (Table 1, entry 3). However, under these conditions, the product was contaminated with $\mathbf{4 a}$ and $\mathbf{5 a}$ leading to difficult isolation (isolated yield of $43 \%)$. The readily available catalyst $\left[\operatorname{Ir}(\mathrm{dtbbpy})(\mathrm{ppy})_{2}\right] \mathrm{PF}_{6}(\mathrm{Ir}-\mathrm{B})$ proved to be a suitable catalyst for the reaction, yielding the cyclized product in $47 \%$ yield (Table 1, entry 4). A screening of bases revealed that $\mathrm{CsOAc}$ was the optimal base. The use of $\mathrm{NaOAc}$ and $\mathrm{Cs}_{2} \mathrm{CO}_{3}$ gave low yields of mono-allylated pyrrolidine 2a (Table 1 Entries 5 and 6). The use of $\left[\operatorname{Ir}(\mathrm{dFppy})_{2}(\mathrm{dtbbpy}) \mathrm{PF}_{6}(\mathrm{Ir}-\mathrm{C})\right.$ afforded the cyclic product $3 a$ in $50 \%$ yield (Table 1, entry 7). Other catalysts presenting suitable redox properties were also tested (for redox properties of the tested catalysts, see supporting information). $R u(b p y)_{3}\left(P F_{6}\right)_{2}$ (Ru-A) and 2,4,5,6-tetrakis(9H-carbazol-9-yl) isophthalonitrile (4CzIPN) afforded the bicycle 3a, together with significant amounts of mono-allylated intermediate $\mathbf{2 a}$ (Table 1, entries 8-9). Eosin $Y$ provide only the mono-allylated product $2 \mathrm{a}$ ( $51 \%$ yield, Table 1 , entry 10$)$. The influence of the radical trap was investigated next. Pleasingly, ethyl 2-(acetoxymethyl)acrylate ${ }^{26}(\mathrm{Y}=\mathrm{OAc})$ gave the desired product in shorter reaction time (Table 1, entry 11) and similar yield than that with the sulfone trap (Table 1, entries 3$)$. The corresponding sulfide trap $(\mathrm{Y}=\mathrm{S}$-tert-docedyl) provided also the desired cyclized product in satisfactory yield (Table 1, Entry 12). However, product isolation was more difficult and the release of one equivalent of a smelly thiol makes the reaction less attractive. Finally, the allyl bromide $(\mathrm{Y}=\mathrm{Br}$ ) was tested and only intermediate $\mathbf{2 a}$ was obtained, with no further conversion to the tropane skeleton 3a (Table 1, Entry 13). Other catalysts (organic photocatalysts), bases $\left(\mathrm{Na}_{2} \mathrm{CO}_{3}, \mathrm{~K}_{2} \mathrm{CO}_{3}\right)$ and solvents (DMF, DME, EtOAc, DCM or MeCN) were tested but were all detrimental to the formation of 3a (see supporting information). Due to shorter reaction time and cleaner product formation, the reaction was further optimized using the allyl acetate trap and catalyst Ir-A. The formation of the bis- 
allylated product $4 \mathbf{a}$ and the bis-addition product $5 \mathbf{a}$ could be minimized by working under higher dilution (0.05 M) and a much shorter reaction time of 20 minutes (Table 1, entry 14). Reducing the catalyst loading to 1 mol\% proved beneficial to the reaction (Table 1, entry 15) and using a smaller excess of the allyl acetate radical trap (1.1 equivalents) did not affect the reaction yield (Table 1, entry 16). Finally, the optimized conditions were used with the corresponding pivalate ( $Y=O P i v)$ and trifluoroacetate $(\mathrm{Y}=$ OTFA) radical traps (Table 1, entries 17 and 18 ) but the yields were lower, particularly with the trifluoroacetate.

Table 1: Optimization of the reaction conditions.

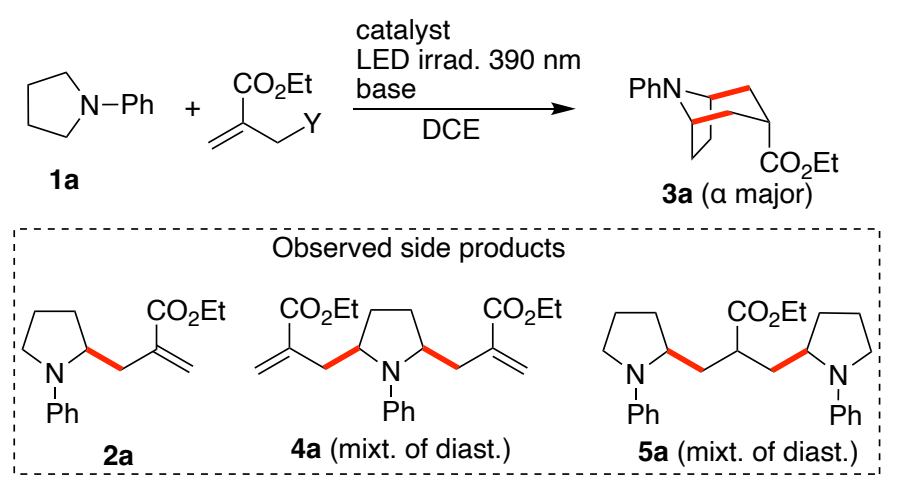

\begin{tabular}{|c|c|c|c|c|c|c|c|}
\hline Entry & Cat (mol\%) & Base (equiv) & $\mathrm{Y}$ (equiv) & Time & [1a] & Yield $^{a}$ & Side product \\
\hline 1 & Ir-A (2) & CsOAc (3.0) & $\mathrm{SO}_{2} \mathrm{Ph}(1.2)$ & $16 \mathrm{~h}$ & $0.1 \mathrm{M}$ & $45 \%^{b}$ & $4 a, 5 a$ \\
\hline 2 & Ir-A (2) & CsOAc (1.2 & $\mathrm{SO}_{2} \mathrm{Ph}(1.2)$ & $16 \mathrm{~h}$ & $0.1 \mathrm{M}$ & $59 \%^{b}$ & $4 a, 5 a$ \\
\hline 3 & $\operatorname{Ir}-\mathrm{A}(2)$ & CsOAc (1.2) & $\mathrm{SO}_{2} \mathrm{Ph}(1.4)$ & $16 \mathrm{~h}$ & $0.1 \mathrm{M}$ & $65 \%^{\mathrm{b}} 43 \% \%^{\mathrm{c}, \mathrm{d}}$ & $4 a, 5 a$ \\
\hline 4 & $\operatorname{Ir}-B(2)$ & CsOAc (1.2) & $\mathrm{SO}_{2} \mathrm{Ph}(1.4)$ & $16 \mathrm{~h}$ & $0.1 \mathrm{M}$ & $47 \%^{b}$ & $4 a, 5 a$ \\
\hline 5 & $\operatorname{Ir}-\mathrm{B}(2)$ & $\mathrm{NaOAc}(1.2)$ & $\mathrm{SO}_{2} \mathrm{Ph}(1.4)$ & $16 \mathrm{~h}$ & $0.1 \mathrm{M}$ & - & $2 \mathrm{a}(26 \%)^{\mathrm{b}}$ \\
\hline 6 & $\operatorname{Ir}-\mathrm{B}(2)$ & $\mathrm{Cs}_{2} \mathrm{CO}_{3}(1.2)$ & $\mathrm{SO}_{2} \mathrm{Ph}(1.4)$ & $16 \mathrm{~h}$ & $0.1 \mathrm{M}$ & - & $2 a(31 \%)^{b}$ \\
\hline 7 & $\operatorname{Ir}-\mathrm{C}(2)$ & CsOAc (1.2) & $\mathrm{SO}_{2} \mathrm{Ph}(1.4)$ & $16 \mathrm{~h}$ & $0.1 \mathrm{M}$ & $50 \%^{\mathrm{b}}$ & $4 a, 5 a$ \\
\hline 8 & Ru-A (2) & CsOAc (1.2) & $\mathrm{SO}_{2} \mathrm{Ph}(1.4)$ & $16 \mathrm{~h}$ & $0.1 \mathrm{M}$ & $30 \%^{\mathrm{b}}$ & $2 a(30 \%)^{b}$ \\
\hline 9 & 4CZIPN (2) & CsOAc (1.2) & $\mathrm{SO}_{2} \mathrm{Ph}(1.4)$ & $16 \mathrm{~h}$ & $0.1 \mathrm{M}$ & $21 \%^{\mathrm{b}}$ & $2 a(31 \%)^{b}$ \\
\hline 10 & Eosin $Y^{f}(2)$ & CsOAc (1.2) & $\mathrm{SO}_{2} \mathrm{Ph}(1.4)$ & $16 \mathrm{~h}$ & $0.1 \mathrm{M}$ & - & $2 \mathrm{a}(51 \%)^{\mathrm{b}}$ \\
\hline 11 & $\operatorname{Ir}-\mathrm{A}(2)$ & CsOAc (1.2) & OAc (1.4) & $8 \mathrm{~h}$ & $0.1 \mathrm{M}$ & $46 \%{ }^{b}$ & none \\
\hline 12 & $\operatorname{Ir}-A(2)$ & CsOAc (1.2) & St-Do (1.4) & $8 \mathrm{~h}$ & $0.1 \mathrm{M}$ & $51 \%^{\mathrm{b}}$ & none \\
\hline 13 & $\operatorname{Ir}-\mathrm{A}(2)$ & CsOAc (1.2) & $\mathrm{Br}(1.4)$ & $8 \mathrm{~h}$ & $0.1 \mathrm{M}$ & - & $2 \mathrm{a}(66 \%)^{\mathrm{b}}$ \\
\hline 14 & $\operatorname{Ir}-\mathrm{A}(2)$ & CsOAc (1.2) & OAc (1.4) & $20 \mathrm{~min}$ & 0.05 & $52 \%^{d}$ & $4 a$ \\
\hline 15 & $\operatorname{Ir}-\mathrm{A}(1)$ & CsOAc (1.2) & OAc (1.4) & $20 \mathrm{~min}$ & 0.05 & $58 \%^{c, d}$ & $4 a$ \\
\hline 16 & $\operatorname{Ir}-\mathrm{A}(1)$ & CsOAc (1.2) & $\mathrm{OAc}(1.1)$ & $20 \mathrm{~min}$ & 0.05 & $57 \%^{d}$ & - \\
\hline 17 & $\operatorname{Ir}-A(1)$ & CsOAc (1.2) & OPiv (1.1) & $20 \mathrm{~min}$ & 0.05 & $45 \%^{d}$ & - \\
\hline 18 & $\operatorname{Ir}-\mathrm{A}(1)$ & CsOAc (1.2) & OTFA (1.1) & $2 \mathrm{~h}$ & 0.05 & $27 \%^{d}$ & - \\
\hline
\end{tabular}


a) Reactions run on $0.2 \mathrm{mmol}$ scale. b) Yield for the major diastereomer determined on the crude product by ${ }^{1} \mathrm{H}$ NMR analysis using ethylene carbonate as a standard. Levels of diastereoselectivity ranging from 5:1 to 7:1. c) Average of 3 runs. d) Isolated yield. f) Irradiation at $325 \mathrm{~nm}$ in DMF as a solvent.

To gain more understanding on the reaction efficiency, cyclization of the pure mono-allylated $\mathbf{2 a}$ product was examined (Scheme 4). The reaction was run in deuterated dichloromethane under identical conditions (catalyst and base) than the annulation process and was monitored by ${ }^{1} \mathrm{H}-\mathrm{NMR}$. Full conversion of $2 \mathbf{a}$ was achieved after 3 hours of irradiation and the bicyclic product 3a resulting from a 6 -endo cyclization was obtained in $72 \%$ yield. The long reaction time necessary to reach full conversion was puzzling since the overall one-pot annulation process was complete within less than 20 minutes. Since acetic acid (one equivalent) is generated during the allylation step leading to $2 a$, the reaction was repeated in the presence of one equivalent of acetic acid. Remarkably, the cyclization was finished in 3 minutes and an improved yield of 91\% was obtained. Running the reaction with CsOPiv (1.2 equiv) and acetic acid (1.0 equiv) afforded the cyclized product in nearly quantitative yield within 2 minutes. This is in accordance with findings reported by Yoon and co-workers where their photocatalytic addition of $\alpha$-aminoalkyl radicals on Michael acceptors was improved by the addition of a Brønsted acids such as TFA. ${ }^{27}$

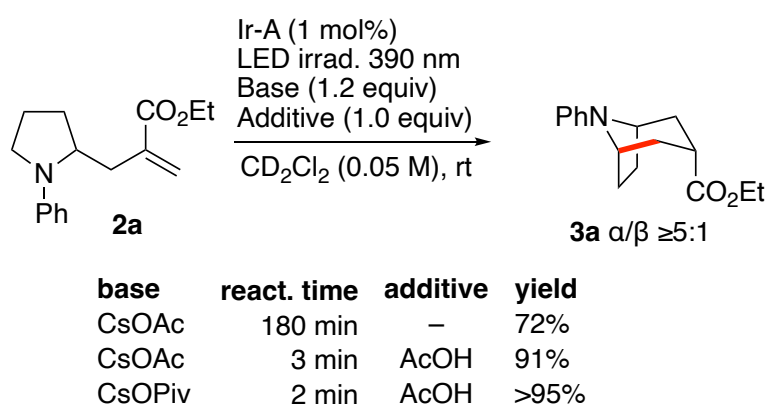

Scheme 4. Cyclization of the mono-allylated pyrrolidine $\mathbf{2 a}$, influence of acid additive.

Adding acetic acid (1 equiv) to the one-pot annulation reaction either at the beginning or during the reaction did not improve the yield indicating that the in situ generated acetic acid was sufficient for the whole process to occur. Running the reaction with CsOPiv (1.2 equivalents) as a base gave results very similar to $\mathrm{CsOAc}$. Overall, these findings show that the optimized conditions for the annulation reaction (Table 1, entry 14 ) do not need to be modified.

Reaction scope. The scope of the reaction was examined using the optimized reaction conditions. At first, different $N$-arylpyrrolidines $1 \mathbf{a}-\mathbf{f}$ were examined (Scheme 5 ). The reaction works well with $p$ substituted $N$-arylpyrrolidines leading to $3 a-3 d$ in $42-57 \%$ yield and good levels of diastereoselectivity in favor of the $\alpha$ isomer $(\alpha / \beta \geq 5: 1)$. The relative configuration of the 3 a was determined by single crystal $X$-ray diffraction crystallography. Interestingly, the electron rich $N$ - $p$-methoxyphenylpyrrolidine 
required longer reaction time despite the fact that this compound is more easily oxidizable, indicating that the critical step of the reaction is probably the deprotonation of the radical cations leading to the $\alpha$-aminoalkyl radicals as discussed by Mariano in his early work (see a discussion of the mechanism, vide infra). ${ }^{28,29}$ In this particular case, the use of the slightly more basic CsOPiv instead of CsOAc provided $3 \mathrm{~d}$ in a good $56 \%$ yield. The presence of ortho-substituent proved to be more problematic as shown by the long reaction time and low yield (20\%) observed for the formation of 3 e.
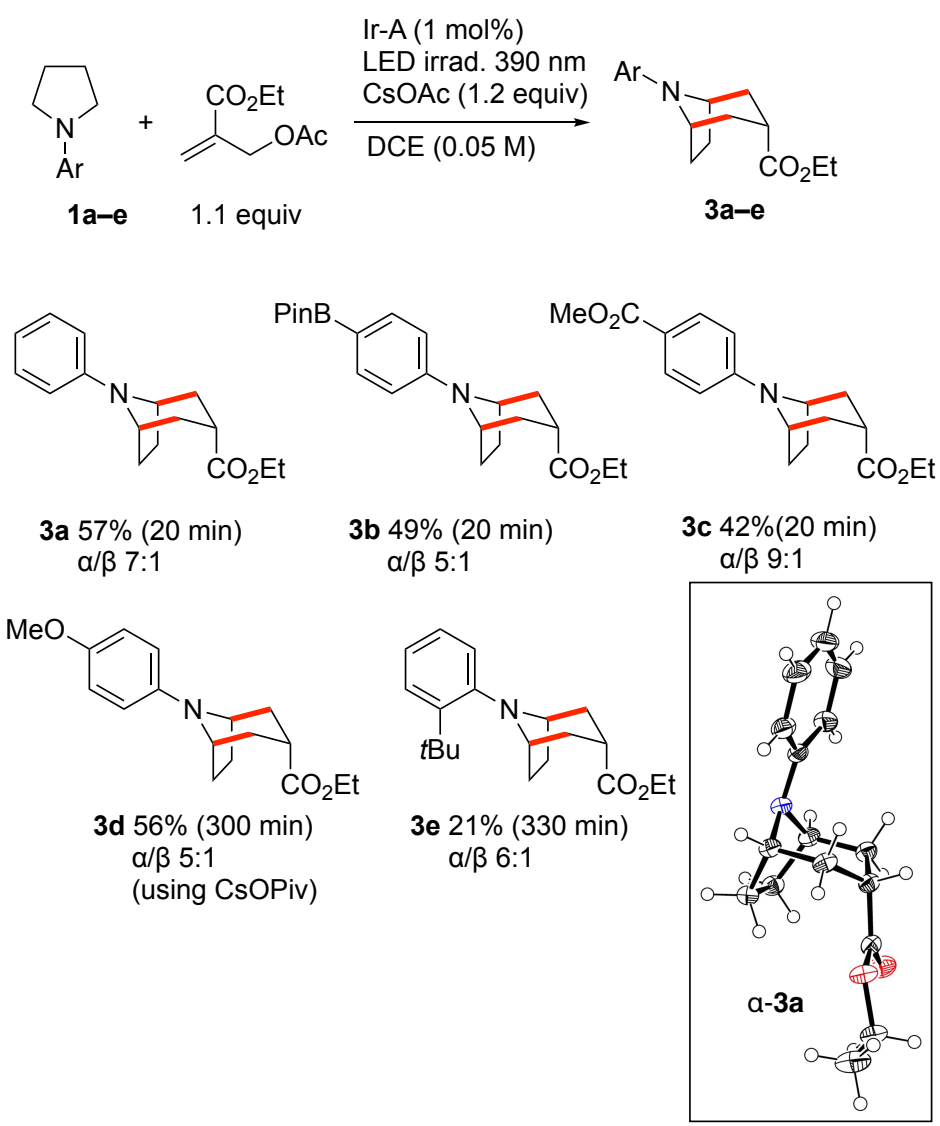

Scheme 5. Tropane skeletons via radical annulation, scope of the N-aryl moiety. X-ray crystal structure of 3a (ellipsoids drawn at 50\% probability, CCDC 2111680).

Next, the use of a 2-substituted pyrrolidine was examined. For this purpose, the 2-methyl substituted $\mathrm{N}$-phenylpyrrolidine $\mathbf{1 f}$ was prepared and submitted to our standard reaction conditions. It afforded the desired bicyclic $\mathbf{3 f}$ containing a quaternary carbon at the bridgehead position in $40 \%$ yield. This result was surpassing our expectation since a difficult regioselectivity control was expected for the second step of the process, i.e. the conversion of $\mathbf{2} \mathbf{f}$ to $\mathbf{3} \mathbf{f}$ via 6-endo-trig cyclization. A study of this cyclization showed that $\mathbf{3 f}$ could be obtained from $\mathbf{2} f$ in $66 \%$ isolated yield indicating that the desired $\alpha$-amino- $\alpha$-methyl radical $\mathbf{R} \mathbf{2} \mathbf{f}$ was preferentially formed over $\mathbf{R} \mathbf{2} f '$. This cyclization yield compared well with the non-methylated substrate $\mathbf{2 a}$ that afforded $\mathbf{3 a}$ in $77 \%$ isolated yield. 

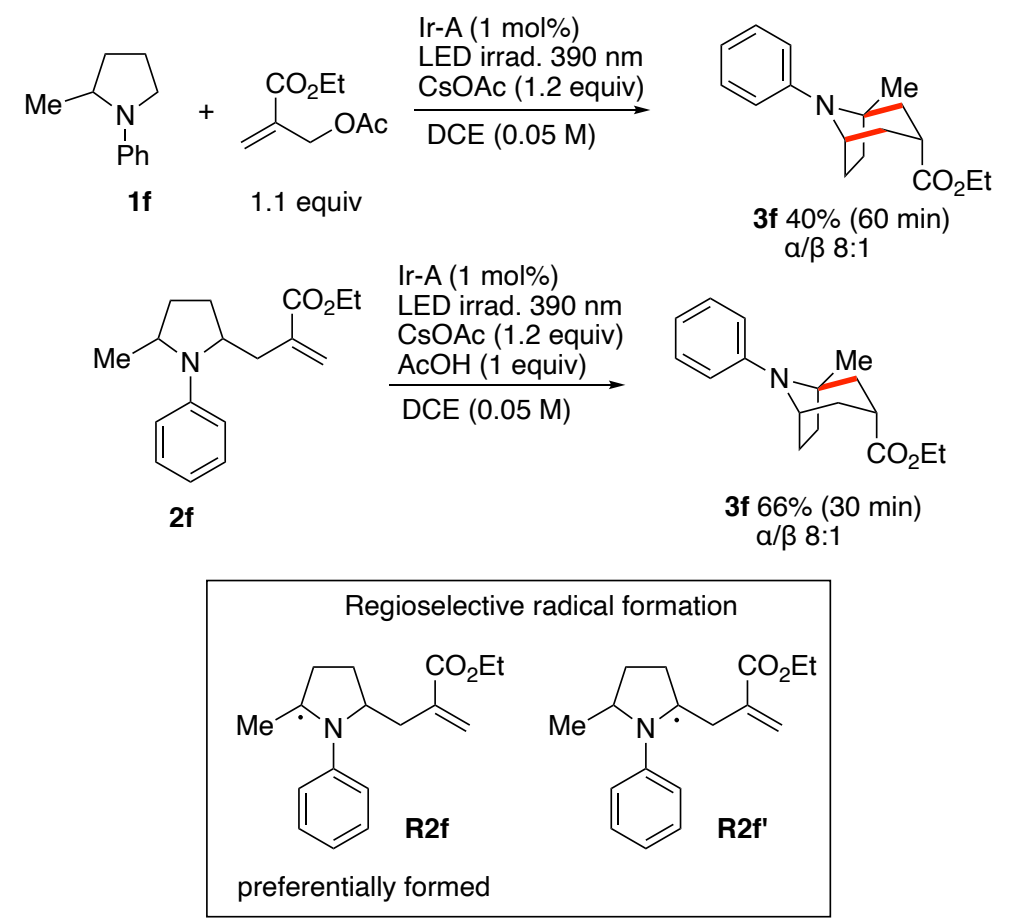

Scheme 6. Annulation reaction of $\mathrm{N}$-phenyl-2-methylpyrrolidine involving a regioselective activation of

\section{2,5-disubstituted pyrrolidine.}

Encouraged by these results, we then turned our attention to the preparation of the homotropane 9azabicyclo[3.3.1]nonane skeleton as well as higher [4.3.1]-analogues (Scheme 7). Piperidine derivatives proved in general to react slightly better than pyrrolidine derivatives. $\mathrm{N}$-Phenylpiperidine 6a gave the cyclized product $8 \mathbf{a}$ in $67 \%$ yield ( $57 \%$ on $3 \mathrm{mmol}$ scale) with an excellent level of diastereoselectivity $(\alpha / \beta>20: 1$ ). The $N$-toluyl derivatives $\mathbf{8 b}-\mathbf{8 d}$ were obtained in similar yields and levels of diastereoselectivity. The electron rich $N$ - $p$-anisyl derivatives in the presence of CsOPiv as a base required longer reaction time and afforded $8 \mathrm{e}$ in lower yield (32\%). Aromatic rings substituted by electron releasing groups afforded the homotropanes $\mathbf{8} \mathbf{f}-\mathbf{8} \mathbf{j}$ in good yields and shorter reaction times in most cases. The $p$-ester substituted homotropane $8 \mathrm{~g}$ was prepared $63 \%$ yield on $1 \mathrm{mmol}$ scale and the $p$-pinacolboryl derivative $\mathbf{8 j}$ in $56 \%$ yield on $3 \mathrm{mmol}$ scale. Gratifyingly, in all the scale-up experiments for $\mathbf{8 a}, \mathbf{8 g}$ and $\mathbf{8 j}$, the catalyst loading could be decreased to $0.5 \mathrm{~mol} \%$. The relative $\alpha$ configuration of $\mathbf{8 g}$ was confirmed by single crystal X-ray diffraction crystallography. Annulations starting from $N$-phenylmorpholine, $N$-phenylpiperazine and $N$-phenylthiomorpholine derivatives $\mathbf{6 k -}$ $\mathbf{m}$ provided the bicyclic amines $\mathbf{8} \mathbf{k}-\mathbf{m}$ in good yields. Remarkably, no products arising from the ringopening of the piperazine ${ }^{30}$ and thiomorpholine ${ }^{31,32}$ were observed. Finally, the reactivity of azepane derivatives were investigated. The $N$-phenyl derivative $6 n$ gave the bicylic amine $8 \mathrm{n}$ in a modest $25 \%$ yield after $14 \mathrm{~h}$. When the reaction was stopped after 10 minutes, the allylated product $\mathbf{7 n}$ was obtained in $65 \%$ yield together with some cyclized product indicating that the 6-endo cyclization was 
probably the yield limiting step. This was confirmed by an independent cyclization attempt starting from $7 n$ that afforded $8 n$ in $24 \%$ yield after two hours, along with $9 \%$ unreacted $7 n$ and some unidentified side products. The $\mathrm{N}$-( $p$-methoxycarbonylphenyl) derivative 60 was also examined. After $9 \mathrm{~h}$ of reaction, only the allylated product $7 \mathrm{o}$ was formed in a low $25 \%$ yield and incomplete conversion.

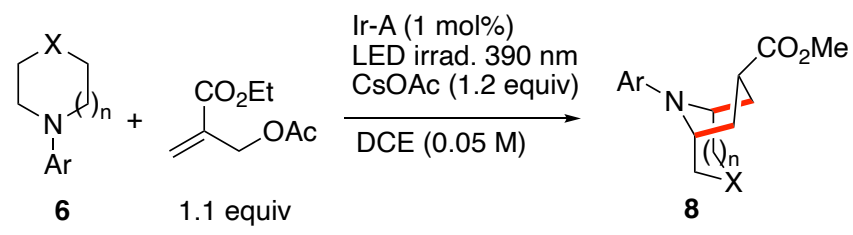

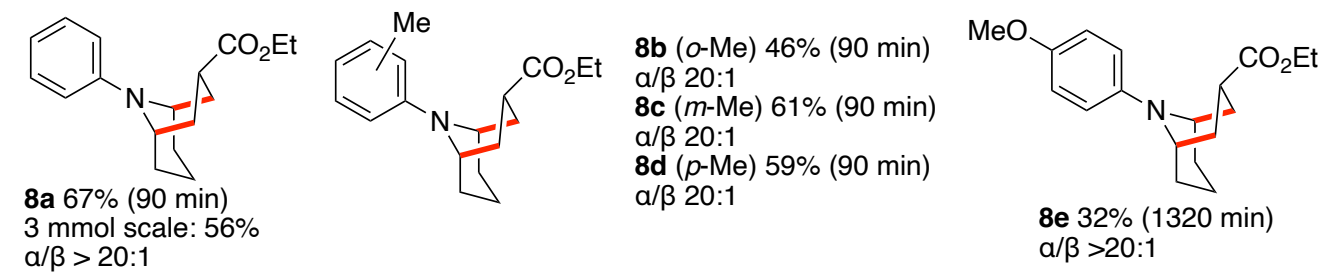<smiles>CCOC(=O)C1CC2CCCC(C1)N2c1ccc(Br)cc1</smiles>

$8 f 30 \%$ (90 $\mathrm{min})$ $a / \beta>20: 1$<smiles>CCOC(=O)C1CC2CCCC(C1)N2c1ccc(C(OC)OC)cc1</smiles>

$8 \mathrm{~g} 65 \%$ (20 min) $1 \mathrm{mmol}$ scale: $63 \%$ $\alpha / \beta>20: 1$<smiles>CCOC(=O)CC1CCCC2CCCC1N2c1ccc(C(C)=O)cc1</smiles>

$8 \mathrm{~h} 42 \%$ (360 $\mathrm{min})$ $\alpha / \beta>20: 1$<smiles>CCOC(=O)CC1CC2CCCC(C1)N2c1ccc(C(F)(F)F)cc1</smiles>

8i $55 \%$ (40 min) $\alpha / \beta>14: 1$

Bpin<smiles>CCOC(=O)CC1CCCC2CCCC1N2c1ccc(I)cc1</smiles>

8j $66 \%$ (20 $\mathrm{min})$ $3 \mathrm{mmol}$ scale: $58 \%$ $\alpha / \beta>4: 1$<smiles>CCOC(=O)C1CC2COCC(C1)N2c1ccccc1</smiles><smiles>CCOC(=O)C1CC2CC([N+](=O)[O-])CC(C1)N2c1ccccc1</smiles>

8k $64 \%$ (20 min) $\alpha / \beta$ 5:1

8I $64 \%(20 \mathrm{~min})$ $\alpha / \beta>12: 1$

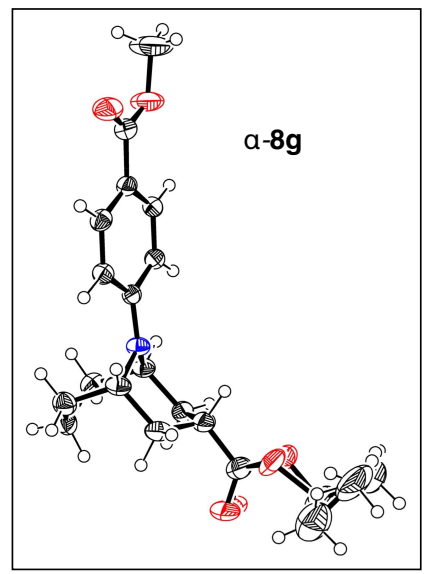<smiles>CCOC(=O)C1CC2CSCC(C1)N2c1ccccc1</smiles>

8m 58\% (20 min) $\alpha / \beta 7: 1$<smiles>CCOC(=O)C1CC2CCCC(C1)N2c1ccccc1</smiles>

8n $25 \%(14 h)$ $\alpha / \beta>20: 1$<smiles>C=C(CC1CCCCCN1c1ccccc1)C(=O)OCC</smiles>

70 25\% (9 h)

(74\% conversion)

Scheme 7. Homotropane [3.3.1] and extended tropane [4.3.1] skeletons via radical annulation. X-ray crystal structures of $\alpha-8 \mathrm{~g}$ (CCDC 2111681), ellipsoids drawn at 50\% probability. 
2-Alkyl-3-ethoxycarbonyl substituted tropanes and homotropanes skeletons are expected to be accessible by using easily available acetylated Baylis-Hillman adducts. In order to test this hypothesis, ethyl 2-(1-acetoxyethyl)acrylate was prepared from the ethyl acrylate and acetaldehyde and reacted with $N$-(p-methoxycarbonylphenyl)piperidine $6 \mathrm{~g}$ (Scheme 8). When 1.1 equivalent of the trap was employed under our standard reaction conditions, prolongated irradiation afforded a mixture of the desired tropane skeleton $\mathbf{1 0}$ together with mono-allylated piperidine $\mathbf{9}$ and the bis-allylated product. Using a 2.5 fold excess of the amine allowed for the formation of the bis-allylated product to be suppressed and, after 10 minutes of irradiation, the intermediate 9 was obtained in $73 \%$ yield and with a good $E$-stereoselectivity ( $E / Z 7: 1$ ). Recrystallization of 9 afforded a virtually diastereomerically pure product $(E / Z>20: 1)$. Gratifyingly, under our optimized cyclization conditions the major $E-9$ afforded 10 in $66 \%$ yield and as a single diastereomer ( $d r>20: 1$ ). However, despite the good results obtained for both steps separately, the one-pot process provided a mixture of $\mathbf{9}$ and $\mathbf{1 0}$. This mixture can be treated under the cyclization conditions to ultimately give the cyclized product $\mathbf{1 0}$ in $\mathbf{7 1 \%}$ yield contaminated with a by-product, presumably a diastereomer. The diester $\mathbf{1 0}$ was converted to corresponding diol 11 whose relative configuration could be determined by single crystal X-ray diffraction crystallography (Scheme 8). The formation of the major diastereomers results presumably from a chair-like transition state as depicted in Scheme 8. 
<smiles>C=C(C(=O)OCC)C(C)OC(C)=O</smiles>

$\mathbf{6 g}$ (2.5 equiv)
Ir-A (1 mol\%)

LED irrad. $390 \mathrm{~nm}$

$\mathrm{CsOAc}$ (1.2 equiv)

$\operatorname{DCE}(0.05 \mathrm{M})$<smiles>C/C=C(/COC)CC1CCCCN1c1ccc(OC(C)=O)cc1</smiles>

$973 \%$ (10 min)

$E / Z 7: 1$ (20:1, after recryst.)

Ir-A (1 mol\%)

LED irrad. $390 \mathrm{~nm}$

CsOAc (1.2 equiv)

$\mathrm{AcOH}$ (1 equiv)

DCE (0.05 M)<smiles>CCOC(=O)C1CC2CCC(C1C)N2c1ccc(C(OC)OCC)cc1</smiles>

10 66\% (240 min) $\mathrm{dr}>20: 1$<smiles>CC1CCC2CCC(CO)C1N2c1ccc(CO)cc1</smiles>
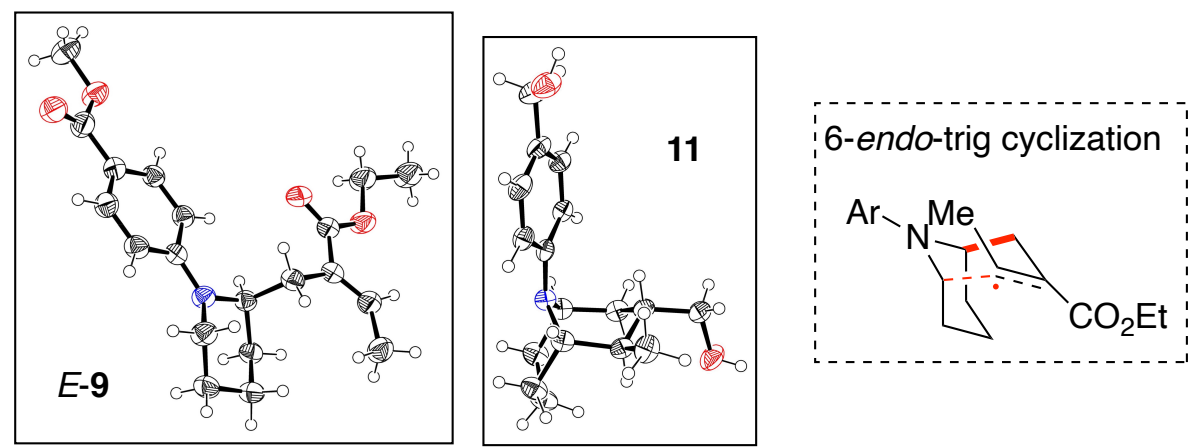

Scheme 8: Diastereoselective preparation of a 2,3-disubsituted [4.4.1]-homotropane. X-Ray crystal structure of E-9 (CCDC 2111682) and 11 (CCDC 2111684), ellipsoids drawn at 50\% probability.

Since most of the bicyclic alkaloids are either secondary amines (nortropanes, homotropanes) or $\mathrm{N}$ methylated tertiary amines (tropanes), it is important to achieve the deprotection of the $\mathrm{N}$-aryl moiety. Methoxyphenyl substituents can be removed under oxidative conditions using chemical oxidants such as cerium ammonium nitrate (CAN) or electrochemical methods. ${ }^{33}$ The cleavage of the $N$ - $p$-MeOPh group of $3 \mathrm{c}$ and $\mathbf{8 e}$ was investigated first and proved to be problematic when an aqueous CAN solution was used ${ }^{34}$ as the quinone liberated during the process reacted with the liberated secondary amines. Gratifyingly, the deprotections were successfully achieved using $\mathrm{CAN}$ in $\mathrm{CH}_{3} \mathrm{CN} /$ water followed by subsequent treatment of the reaction mixture with sodium borohydride to reduce the quinone, then with benzyl chloroformate to prepare their $\mathrm{N}$-Cbz-protected form. ${ }^{35}$ Under these conditions, the desired Cbz-protected nortropane 12 and homotropane 13 were obtained in 90\% and 80\% yields, 
respectively, without erosion of the diastereomeric ratio (Scheme 9A). The Cbz-protecting group was introduced to facilitate product purification but also for both its facile deprotection and conversion to the corresponding $N$-methyl derivative. ${ }^{36}$ Since annulation reactions with the $N$ - $p$-MeOPh substituted cyclic amines were slow and moderately efficient, we also investigated the deprotection of the $N-(p-$ pinacolboryl)phenyl derivative $\mathbf{8 j}$ that was formed in good yield. The dearylation of $\mathbf{8 j}$ to $\mathbf{1 3}$ (Scheme 9B) was conveniently performed in $71 \%$ yield by perboric acid treatment, affording after simple extraction the crude phenol, followed by $\mathrm{CAN}$ and $\mathrm{Cbz} C$ treatment according to the optimized procedure developed for the para-methoxy derivatives $3 \mathrm{c}$ and $8 \mathrm{e}$.

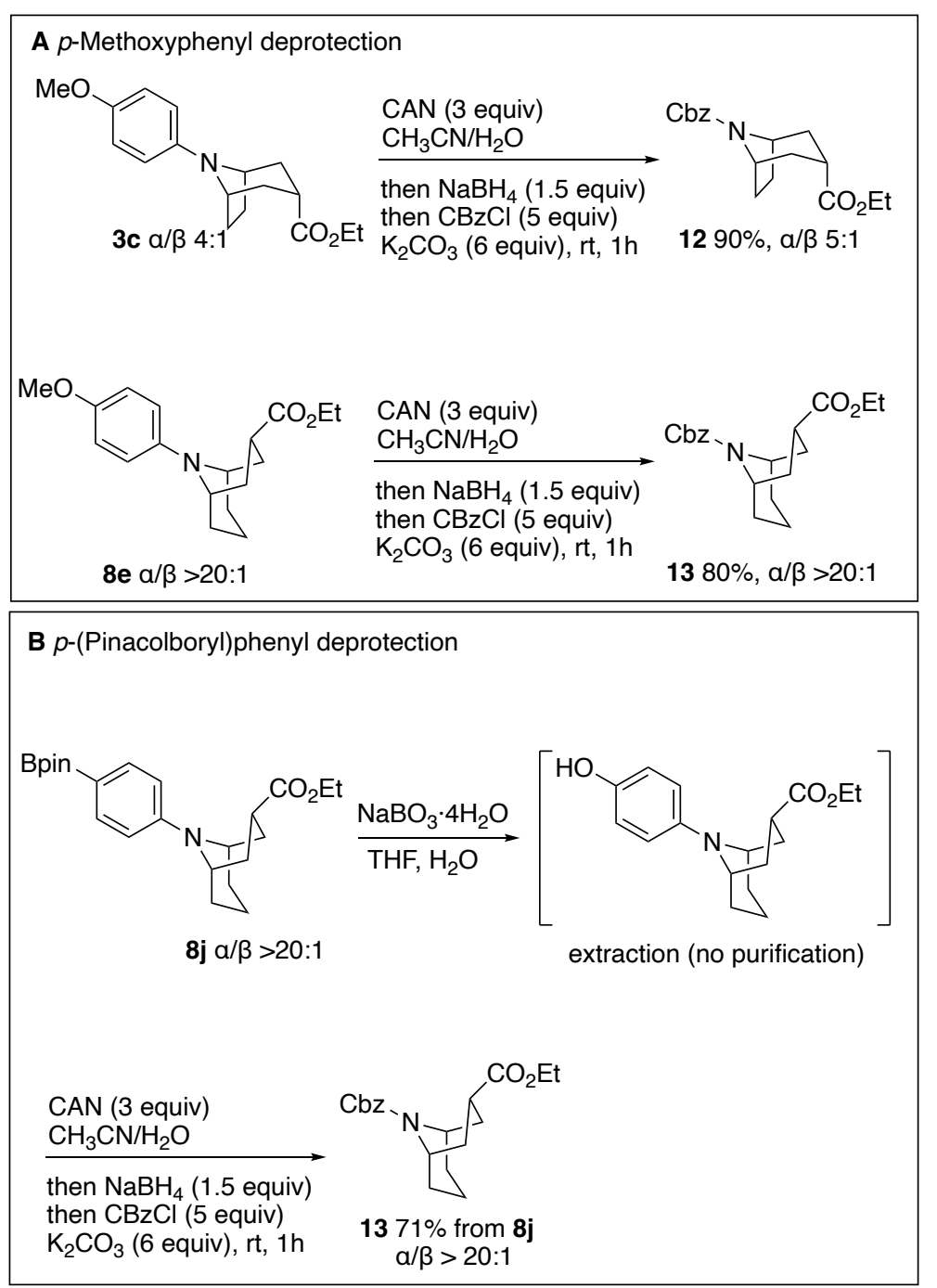

Scheme 9. Dearylation of the $N$-MeOPh and $N-p$-pinBPh derivatives $\mathbf{8 e}$ and $\mathbf{8 j}$.

Finally, we hypothesized that the major $\alpha$-ethoxycarbonyl substituted tropanes and homotropanes were formed by kinetic protonation of the intermediate enolate from the less hindered exo-face (see mechanism, Scheme 11). Epimerization of $\alpha$-stereoisomers to the more stable $\beta$-products was therefore examined. Heating the ester $3 a$ and $8 a$ at $40^{\circ} \mathrm{C}$ in ethanol in the presence of sodium ethoxide 
afforded the $\beta$ isomers in good to excellent levels of diastereoselectivity (Scheme 10). This strategy is expected to be useful for the stereocontrolled synthesis of tropanes and homotropane alkaloids.<smiles>CCOC(=O)C1CC2CCC(C1)N2c1ccccc1</smiles>

3a $a / \beta$ 5:1<smiles>CCOC(=O)OCC</smiles>

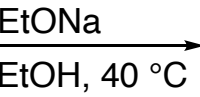

$8 \mathrm{a} a / \beta>20: 1$<smiles>CCOC(=O)C1CC2CCC(C1)N2c1ccccc1</smiles>

3a $79 \%, \alpha / \beta<1: 20$<smiles>CCOC(=O)C1CC2CCCC(C1)N2c1ccccc1</smiles>

8 a $76 \%, a / \beta<1: 8$

\section{Scheme 10. Thermodynamic epimerization of tropane and homotropane derivatives}

Mechanism. As mentioned in the introduction, the photocatalytic generation of $\alpha$-aminoalkyl radicals from cyclic anilines and their subsequent intermolecular addition to Michael acceptors are wellestablished processes. However, the selectivity of the reaction sequence responsible for the annulation process is quite unique and deserves to be discussed (Scheme 11). Upon blue light irradiation the catalyst Ir-A reaches its excited state $\operatorname{Ir}(\mathrm{III}) *\left(\mathrm{E}_{\mathrm{ox}} \mathrm{Ir}(\mathrm{III} * / \mathrm{II})=+1.21 \mathrm{~V} \mathrm{SCE} \text { in MeCN }\right)^{37}$ and is able to oxidize $N$-phenylpyrrolidine 1 a to its aminium radical cation $\mathrm{RC1a}\left(\mathrm{E}_{\mathrm{red}}=+0.62 \mathrm{~V} / \mathrm{SCE}\right.$ in $\mathrm{MeCN}$ ), which generates the $\alpha$-aminoalkyl radical R1a upon deprotonation. This nucleophilic radical adds to the electron-poor double bond of the allylic trap, leading to an intermediate $\alpha$-ester radical RE2a. The reduction potential of the tertiary radical RE2a is estimated to be $E_{\text {red }}>-0.29$ V SCE (see supporting information for details). Such a radical is expected to be readily reduced by the $\operatorname{Ir}($ II) species $\left(\mathrm{E}_{\text {red }} \operatorname{Ir}(\mathrm{III} / \mathrm{II})=-1.37 \mathrm{~V} / \mathrm{SCE}\right),{ }^{37}$ thus closing the first catalytic cycle and providing a transient enolate intermediate that produces the mono-allylated pyrrolidine $\mathbf{2}$ a upon $\beta$-fragmentation. The intermediate $2 \mathbf{a}$ is now able to enter the second catalytic cycle. After oxidation of $\mathbf{2 a}$ and subsequent deprotonation, the $\alpha$-aminoalkyl radical $\mathbf{R} 2 \mathbf{a}$ is formed selectively. The latter undergoes a 6-endo-trig cyclization, leading to the bicyclic $\alpha$-ester radical RE3a whose calculated reduction potential $\left(\mathrm{Er}_{\mathrm{ed}}=-0.77 \mathrm{~V} \mathrm{SCE}\right.$, see supporting information for details) is in good agreement with the experimental value of $\mathrm{E}_{\mathrm{red}}=-$ $0.66 \mathrm{~V}$ SCE reported for the secondary $\alpha$-ester radical $\mathrm{CH}_{3} \mathrm{CH}(\bullet) \mathrm{CO}_{2} \mathrm{Me}^{38}$ This allows for its facile reduction by the $\operatorname{Ir}(\mathrm{II})$ species, thus closing the second catalytic cycle. exo-Selective protonation of the transient enolate ultimately delivers the desired bicyclic product $\mathbf{3 a}$.

The success of this approach relies on three key features. Firstly, the radical cation RC2a needs to be regioselectively deprotonated to form the radical $\mathbf{R 2 a}$. No product results resulting from $\mathbf{R 2} \mathbf{a}$ ' has been identified but we cannot exclude that such products are formed in small amount (Scheme 11A). The 
calculated $\mathrm{pK}_{\mathrm{a}}$ values for the $\mathrm{C}(2)-\mathrm{H}$ and $\mathrm{C}(3)-\mathrm{H}$ bond (see scheme $11 \mathrm{~A}$ ) are very close and cannot be used to rationalize this result. Nevertheless, this type of selectivity for the less substituted position is well-established and can be rationalized by both steric and stereoelectronic effects. ${ }^{39-44}$ Secondly, in principle all three amines $1 \mathbf{a}, \mathbf{2} \mathbf{a}$ and $\mathbf{3 a}$ present in solution can be easily oxidized by the $\operatorname{Ir}(\mathrm{III})^{*}$ catalyst excited state. However, only RC1a and RC2a (calculated $\mathrm{pK}_{\mathrm{a}} 51.4$ and 52.7 in DCE) are undergoing $1=$ ${ }^{6}$ deprotonation to generate $\alpha$-aminoalkyl radicals. The deprotonation of the bicyclic radical RC3a (pKa 58.4) is much less favorable and no product resulting from the bicyclic radical R3a has been observed (Scheme 11B). A separate attempt to achieve allylation of pure 3a under our standard reaction conditions led only to partial decomposition of the starting material without formation of an allylated product. Since the oxidation potentials of all three amines $\mathbf{1} \mathbf{a}, \mathbf{2} \mathbf{a}$ and $\mathbf{3} \mathbf{a}$ are close and well below the oxidation potential of the excited $\operatorname{Ir}(I I I)^{*}$ catalyst, we believe that the efficacy of the whole process is due to the fact that oxidation of $3 a$, which is becoming increasingly important as the reaction proceeds, is not leading to its decomposition as long as $\mathbf{1} \mathbf{a}$ and $\mathbf{2} \mathbf{a}$ are present in solution due to rapid electron transfers between the different amines in solution (Scheme 11C). Such rapid electron transfers involving radical cations are well-documented in the literature ${ }^{45-47}$ and have led to the use of triarylaminium radical cation as organic mediator in electro-organic synthesis. ${ }^{48-51}$ 

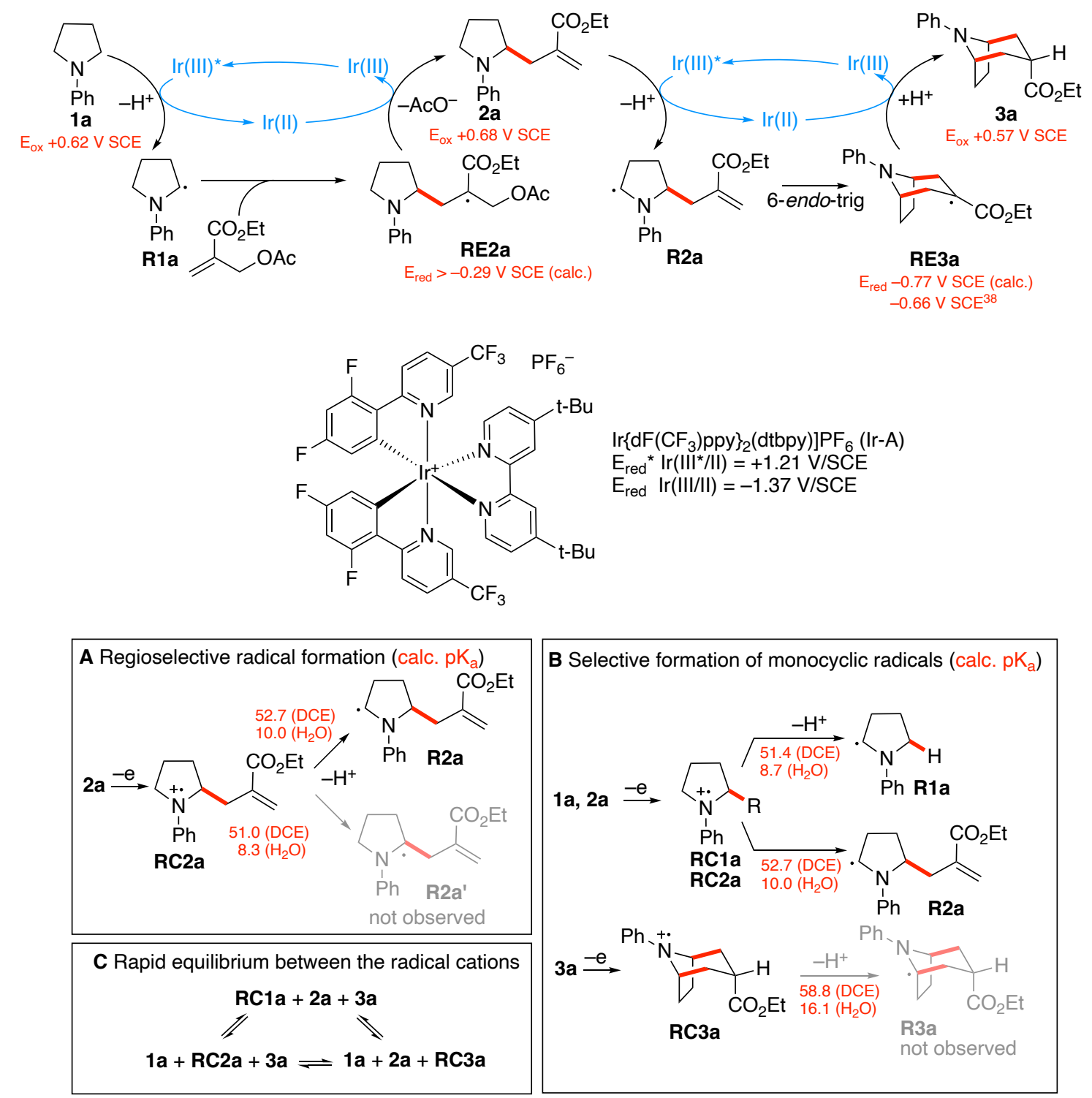

Scheme 11. Possible mechanism for the [3+3] radical annulation and analysis of $(A)$ the regioselectivity of radical formation, (B) the selective formation of bicyclic radicals, and (C) the equilibrium between the different radical cations formed during the reaction.

The proposed mechanism suggests that the efficiency of the annulation process is dictated by the formation of a final product that cannot deliver efficiently an $\alpha$-aminoakyl radical due to an unfavorable (or less favorable) deprotonation step. This may explain the difficulties and low yield observed in the annulation of azepanes leading to [4.3.1] bicycles (see formation of $8 \mathrm{n}$ in Scheme 7), for which the larger bicyclic systems are expected to favor deprotonation due to an increase of conformational flexibility leading to product and catalyst degradation. This assumption is supported by calculations, the oxidation potential of $8 n\left(E_{o x}+0.66 \mathrm{~V} / \mathrm{SCE}\right)$ lying within the range of our catalyst and the $\mathrm{pK}_{a}$ of the corresponding radical cation $\mathrm{RC} 8 \mathrm{n}\left(\mathrm{pK}_{\mathrm{a}} 49.5\right.$ (DCE), $6.8\left(\mathrm{H}_{2} \mathrm{O}\right)$ ) being far below the 
ones of the less flexible RC3a ( $\mathrm{pK}_{a} 58.8$ (DCE), $16.1\left(\mathrm{H}_{2} \mathrm{O}\right)$ ) and RC8a (pKa 57.1 (DCE), $14.4\left(\mathrm{H}_{2} \mathrm{O}\right)$ ) and similar to the one of the monocyclic amines.

Counter-intuitively, the reactions with electron-enriched aniline systems such as $\mathrm{N}$-(paramethoxyphenyl)pyrrolidine 1d (to form 3d, see Scheme 5) and $N$-(para-methoxyphenyl)piperidine 6e (to form 8e, Scheme 7) were more difficult than those with electron-poorer systems. They required much longer reaction times and, in the case of $\mathbf{1 d}$, the use of a slightly stronger base. This indicates that the critical step of the process is probably not the amine oxidation but rather the deprotonation of the radical cation. Calculations showed that the more stable para-methoxyphenyl substituted radical cation $\mathbf{R C 1} \mathbf{d}$ is also much less acidic $\left(\mathrm{pK}_{\mathrm{a}}=+57.1(\mathrm{DCE}) /+14.4\left(\mathrm{H}_{2} \mathrm{O}\right)\right)$ than $\mathbf{R C 1 a}\left(\mathrm{pK}_{\mathrm{a}}=+51.4\right.$ $\left.(D C E) /+8.7\left(\mathrm{H}_{2} \mathrm{O}\right)\right)$. The electrochemical investigation of $\mathbf{1} \mathbf{d}$ by cyclic voltammetry provided a quasi reversible oxidation wave in the absence of added base (Figure 2, A) whilst the simple $\mathrm{N}$ phenylpyrrolidine 1a produced irreversible oxidation event (see supporting information). ${ }^{52,53}$ The addition of cesium pivalate drastically changed the cyclic voltammogram of $\mathbf{1} \mathbf{d}$ and two oxidation waves were observed (Figure 2, B). A first irreversible oxidation wave appeared at a slightly lower oxidation potential than the oxidation event of the amine alone. This shift of potential relative to the cyclic voltammogram in the absence of base is attributed to an oxidation event of the amine interacting with cesium pivalate, possibly a proton-coupled electron transfer (PCET) process. ${ }^{54,55}$ The second wave, whose potential corresponds to the oxidation event observed in the absence of base, becomes less reversible in presence of cesium pivalate. The voltammogram of the tropane $\mathbf{3 d}$ (Figure 2, C) indicates as anticipated a reversible oxidation process. Interestingly, it is almost not affected by the presence of cesium pivalate indicating that the bicyclic cation radical of $\mathbf{3} \mathbf{d}$ is not deprotonated by the base during the measurement (Figure 2, D). This observation supports the proposed mechanism and the fact that the photoredox annulation process stops at the bicyclic stage. 


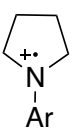

RC1d $\mathrm{Ar}=p-\mathrm{MeOPh}$ 57.1 (DCE) $14.4\left(\mathrm{H}_{2} \mathrm{O}\right)$

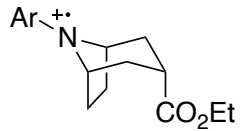

RC3d $\mathrm{Ar}=p-\mathrm{MeOPh}$

$65.2(\mathrm{DCE}) 22.5\left(\mathrm{H}_{2} \mathrm{O}\right)$
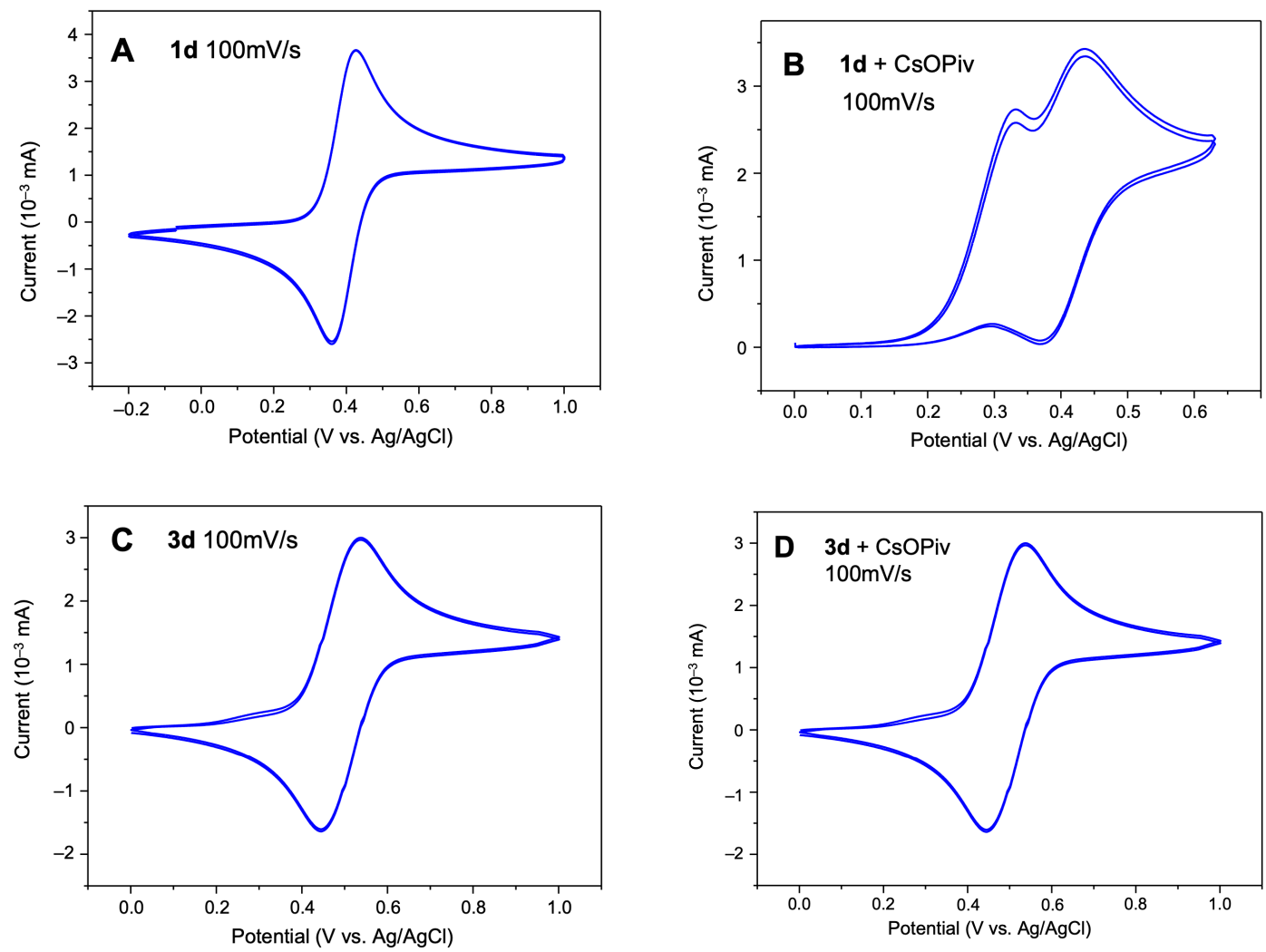

Figure 2. Cyclic voltammograms of $N$-p-methoxyphenylamines $1 \mathbf{d}$ and $\mathbf{3 d}(1 \mathrm{mM})$ in the absence (A and C) and in the presence of cesium pivalate $(1.2 \mathrm{mM})(B$ and $D)$. Voltammograms were recorded in acetonitrile containing $\left[\mathrm{Bu}_{4} \mathrm{~N}\right]\left[\mathrm{PF}_{6}\right](0.1 \mathrm{M})$ as a supporting electrolyte.

The hypothesis that the reactions stop at the bicyclic stage due to inefficient deprotonation of the bicyclic radical cations offers the opportunity to run a more complex reaction process involving a bisannulation process starting from a tertiary acyclic aniline derivative and ending with an oxidationresistant bicyclic system. This assumption was tested with $N, N$-dimethyl aniline. In the presence of 2.2 equivalents of the allylic acetate radical trap added in two portions (at the beginning of the reaction and after 15 minutes), the product of bis-annulation product 14 was isolated in $13 \%$ yield with good stereocontrol. By starting from $N$-methyl- $N$-trimethylsilylmethylaniline, the yield for the formation of 14 could be improved to $22 \%$. In this process, the product of the first annulation (Scheme 12 , blue bond formation) leads to a piperidine derivative that can further react via a second annulation process (Scheme 12, red bond formation) to produce 14. All attempts to stop at the piperidine stage gave complex inseparable mixture of products. 


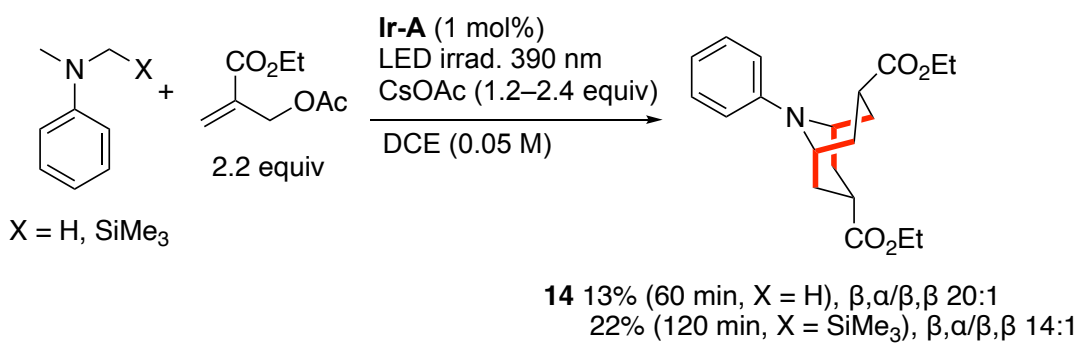

Scheme 12. Synthesis of a homotropane skeleton via a double [3+3] annulation reaction

\section{Conclusion}

In summary, we have developed a new annulation strategy for the synthesis of bicyclic alkaloid skeletons. The reactions take place under mild conditions and afford tropane and homotropane frameworks in good yields and good to excellent levels of diastereoselectivity starting from simple and readily available starting materials using visible-light photoredox catalysis. This annulation process takes advantage of the unique reactivity of ethyl 2-(acetoxymethyl)acrylate as a 1,3-bis radical acceptor and of cyclic $\mathrm{N}, \mathrm{N}$-dialkylanilines as radical 1,3-bis radical donor. Application of this rapid method for the assembly of alkaloid natural products and related biologically relevant molecules is currently under investigation.

\section{Acknowledgements}

This work was supported by the Swiss National Science Foundation (project 200021L_182078) and the ANR (project ANR-18-CE93-0004) under the Lead Agency and International Co-Investigator Scheme. V.M. and J.-M. M thank the Labex ARCANE (ANR-11-LABX-0003) and CBH-EUR-GS (ANR-17-EURE-0003) for partial funding.

\section{Author contributions}

E.C. F.D. and P.R. designed the synthetic experiments. E.C. executed all the synthetic work and analyzed the data. J.-M.M. performed the calculations in collaboration with V.M.. J.A., A.D and V.M. designed and run the electrochemical studies and analyzed the data. E.C., F.D. and P.R. co-wrote the manuscript. All the authors discussed the results and commented on the manuscript.

\section{Competing interests}

The authors declare no competing interests.

\section{References}

1. Kohnen-Johannsen, K. L. \& Kayser, O. Tropane Alkaloids: Chemistry, Pharmacology, Biosynthesis and Production. Molecules 24, 796 (2019). 
2. Lima, D. J. P., Santana, A. E. G., Birkett, M. A. \& Porto, R. S. Recent progress in the synthesis of homotropane alkaloids adaline, euphococcinine and N-methyleuphococcinine. Beilstein J. Org. Chem. 17, 28-41 (2021).

3. Robinson, R. LXIII._A synthesis of tropinone. J. Chem. Soc. Trans. 111, 762-768 (1917).

4. Medley, J. W. \& Movassaghi, M. Robinson's landmark synthesis of tropinone. Chem. Commun. 49, 10775-10777 (2013).

5. Afewerki, S., Wang, J.-X., Liao, W.-W. \& Córdova, A. Chapter Three - The Chemical Synthesis and Applications of Tropane Alkaloids. in The Alkaloids: Chemistry and Biology (ed. Knölker, H.-J.) vol. 81 151-233 (Academic Press, 2019).

6. Ikeda, M., Kugo, Y., Kondo, Y., Yamazaki, T. \& Sato, T. Regioselective synthesis of bridged azabicyclic compounds using radical translocations/cyclisations of methyl 2-alkynyl-1-(oiodobenzoyl)pyrrolidine-2-carboxylates: a formal total synthesis of ( \pm )-epibatidine. J. Chem. Soc. Perkin 1 3339-3344 (1997) doi:10.1039/A705226J.

7. Huang, J.-P. et al. Tropane alkaloid biosynthesis: a centennial review. Nat. Prod. Rep. (2021) doi:10.1039/D0NP00076K.

8. Curran, D. P. Radical Reactions and Retrosynthetic Planning. Synlett 1991, 63-72 (1991).

9. Dowd, Paul. \& Zhang, Wei. Free radical-mediated ring expansion and related annulations. Chem. Rev. 93, 2091-2115 (1993).

10. McCarroll, A. J. \& Walton, J. C. Organic syntheses through free-radical annulations and related cascade sequences. J. Chem. Soc. Perkin 1 3215-3229 (2001) doi:10.1039/B105234A.

11. Rheault, T. R. \& Sibi, M. P. Radical-Mediated Annulation Reactions. Synthesis 2003, 803-819 (2003).

12. Feng, J. \& Liu, B. Formal carbo [3+3] annulation and its application in organic synthesis. Tetrahedron Lett. 56, 1474-1485 (2015).

13. Lewis, F. D. Proton-transfer reactions of photogenerated radical ion pairs. Acc. Chem. Res. 19, 401405 (1986). 
14. Nakajima, K., Miyake, Y. \& Nishibayashi, Y. Synthetic Utilization of $\alpha$-Aminoalkyl Radicals and Related Species in Visible Light Photoredox Catalysis. Acc. Chem. Res. 49, 1946-1956 (2016).

15. Wayner, D. D. M., Dannenberg, J. J. \& Griller, D. Oxidation potentials of $\alpha$-aminoalkyl radicals: bond dissociation energies for related radical cations. Chem. Phys. Lett. 131, 189-191 (1986).

16. Condie, A. G., González-Gómez, J. C. \& Stephenson, C. R. J. Visible-Light Photoredox Catalysis: AzaHenry Reactions via C-H Functionalization. J. Am. Chem. Soc. 132, 1464-1465 (2010).

17. Freeman, D. B., Furst, L., Condie, A. G. \& Stephenson, C. R. J. Functionally Diverse Nucleophilic Trapping of Iminium Intermediates Generated Utilizing Visible Light. Org. Lett. 14, 94-97 (2012).

18. Hu, J., Wang, J., Nguyen, T. H. \& Zheng, N. The chemistry of amine radical cations produced by visible light photoredox catalysis. Beilstein J. Org. Chem. 9, 1977-2001 (2013).

19. Jeon, Y. T., Lee, C. P. \& Mariano, P. S. Radical cyclization reactions of alpha-silyl amine alpha, betaunsaturated ketone and ester systems promoted by single electron transfer photosensitization. J. Am. Chem. Soc. 113, 8847-8863 (1991).

20. Pandey, G., Lakshmaiah, G. \& Kumaraswamy, G. A new and efficient strategy for non-stabilized azomethine ylide via photoinduced electron transfer (PET) initiated sequential double desilylation. J. Chem. Soc. Chem. Commun. 1313-1314 (1992) doi:10.1039/C39920001313.

21. Kohls, P., Jadhav, D., Pandey, G. \& Reiser, O. Visible Light Photoredox Catalysis: Generation and Addition of N-Aryltetrahydroisoquinoline-Derived $\alpha$-Amino Radicals to Michael Acceptors. Org. Lett. 14, 672-675 (2012).

22. Miyake, Y., Nakajima, K. \& Nishibayashi, Y. Visible-Light-Mediated Utilization of $\alpha$-Aminoalkyl Radicals: Addition to Electron-Deficient Alkenes Using Photoredox Catalysts. J. Am. Chem. Soc. 134, 3338-3341 (2012).

23. Noble, A. \& MacMillan, D. W. C. Photoredox $\alpha$-Vinylation of $\alpha$-Amino Acids and N-Aryl Amines. J. Am. Chem. Soc. 136, 11602-11605 (2014).

24. Dai, X. et al. The Coupling of Tertiary Amines with Acrylate Derivatives via Visible-Light Photoredox Catalysis. J. Org. Chem. 79, 7212-7219 (2014). 
25. Leng, L., Fu, Y., Liu, P. \& Ready, J. M. Regioselective, Photocatalytic $\alpha$-Functionalization of Amines. J. Am. Chem. Soc. 142, 11972-11977 (2020).

26. Dai, X. et al. The Coupling of Tertiary Amines with Acrylate Derivatives via Visible-Light Photoredox Catalysis. J. Org. Chem. 79, 7212-7219 (2014).

27. Ruiz Espelt, L., Wiensch, E. M. \& Yoon, T. P. Brønsted Acid Cocatalysts in Photocatalytic Radical Addition of $\alpha$-Amino C-H Bonds across Michael Acceptors. J. Org. Chem. 78, 4107-4114 (2013).

28. Zhang, X. et al. Dynamics of alpha-CH Deprotonation and alpha-Desilylation Reactions of Tertiary Amine Cation Radicals. J. Am. Chem. Soc. 116, 4211-4220 (1994).

29. Dombrowski, G. W. et al. Efficient Unimolecular Deprotonation of Aniline Radical Cations. J. Org. Chem. 70, 3791-3800 (2005).

30. Cai, S. et al. Visible-Light-Promoted C-C Bond Cleavage: Photocatalytic Generation of Iminium Ions and Amino Radicals. Angew. Chem. Int. Ed. 51, 8050-8053 (2012).

31. Surzur, J.-M., Crozet, M.-P. \& Dupuy, C. Synthese de systemes thiacyclohexaniques and thiacycloheptaniques par addition radicalaire intramoleculaire du radical thiyle. Tetrahedron Lett. 12, 2025-2028 (1971).

32. McCourt, R. \& Scanlan, E. M. 5-exo versus 6-endo Thiyl-Radical Cyclizations in Organic Synthesis. Helv. Chim. Acta 102, e1900162 (2019).

33. De Lamo Marin, S., Martens, T., Mioskowski, C. \& Royer, J. Efficient N-p-Methoxyphenyl Amine Deprotection through Anodic Oxidation. J. Org. Chem. 70, 10592-10595 (2005).

34. Xu, G.-Q. et al. Metal-Free $\alpha-C(s p 3)-H$ Aroylation of Amines via a Photoredox Catalytic RadicalRadical Cross-Coupling Process. Org. Lett. 23, 2846-2852 (2021).

35. Taniyama, D., Hasegawa, M. \& Tomioka, K. A facile and efficient asymmetric synthesis of (+)salsolidine. Tetrahedron Lett. 41, 5533-5536 (2000).

36. Sardina, F. J., Howard, M. H., Koskinen, A. M. P. \& Rapoport, H. Chirospecific synthesis of nitrogen and side chain modified analogs of (+)-anatoxin. J. Org. Chem. 54, 4654-4660 (1989). 
37. Teegardin, K., Day, J. I., Chan, J. \& Weaver, J. Advances in Photocatalysis: A Microreview of Visible Light Mediated Ruthenium and Iridium Catalyzed Organic Transformations. Org. Process Res. Dev. 20, 1156-1163 (2016).

38. Bortolamei, N., Isse, A. A. \& Gennaro, A. Estimation of standard reduction potentials of alkyl radicals involved in atom transfer radical polymerization. Electrochimica Acta 55, 8312-8318 (2010).

39. Lewis, F. D. Proton-transfer reactions of photogenerated radical ion pairs. Acc. Chem. Res. 19, 401405 (1986).

40. Lewis, F. D., Ho, T.-I. \& Simpson, J. T. Photochemical addition of tertiary amines to stilbene. Stereoelectronic control of tertiary amine oxidation. J. Org. Chem. 46, 1077-1082 (1981).

41. Barry, J. E., Finkelstein, M., Mayeda, E. A. \& Ross, S. D. Products and mechanisms in the anodic oxidation of N,N-dimethylbenzylamine in methanol. J. Org. Chem. 39, 2695-2699 (1974).

42. Eberson, L. et al. Studies on Electrolytic Substitution Reactions. IX. Anodic Cyanation of Aromatic Ethers and Amines in Emulsions with the Aid of Phase Transfer Agents. Acta Chem. Scand. 29b, 451-456 (1975).

43. Smith, J. R. L. \& Masheder, D. Amine oxidation. Part IX. The electrochemical oxidation of some tertiary amines: the effect of structure on reactivity. J. Chem. Soc. Perkin Trans. 2 47-51 (1976) doi:10.1039/P29760000047.

44. Xie, J., Rudolph, M., Rominger, F. \& Hashmi, A. S. K. Photoredox-Controlled Mono- and DiMultifluoroarylation of C(sp3)-H Bonds with Aryl Fluorides. Angew. Chem. Int. Ed. 56, 7266-7270 (2017)

45. Ledwith, A. Cation radicals in electron transfer reactions. Acc. Chem. Res. 5, 133-139 (1972).

46. Workentin, M. S., Johnston, L. J., Wayner, D. D. M. \& Parker, V. D. Reactivity of Aromatic Radical Cations. Rate Constants for Reactions of 9-Phenyl- and 9,10-Diphenylanthracene Radical Cations with Acyclic Amines. J. Am. Chem. Soc. 116, 8279-8287 (1994). 
47. Beresford, P., C. Lambert, M. \& Ledwith, A. Cation radicals: ring opening of a cyclobutane by electron transfer. J. Chem. Soc. C Org. 0, 2508-2510 (1970).

48. Connelly, N. G. \& Geiger, W. E. Chemical Redox Agents for Organometallic Chemistry. Chem. Rev. 96, 877-910 (1996).

49. Steckhan, E. Indirect Electroorganic Syntheses-A Modern Chapter of Organic Electrochemistry [New Synthetic Methods (59)]. Angew. Chem. Int. Ed. Engl. 25, 683-701 (1986).

50. Steckhan, E. Organic syntheses with electrochemically regenerable redox systems. in Electrochemistry I (ed. Steckhan, E.) 1-69 (Springer, 1987). doi:10.1007/3-540-17871-6_11.

51. Quiroz-Guzman, M. \& Brown, S. N. Tris(4-bromo-phenyl)aminium hexa-chloridoantimonate ('Magic Blue'): a strong oxidant with low inner-sphere reorganization. Acta Crystallogr. C 66, m171-m173 (2010).

52. Seo, E. T. et al. Anodic Oxidation Pathways of Aromatic Amines. Electrochemical and Electron Paramagnetic Resonance Studies. J. Am. Chem. Soc. 88, 3498-3503 (1966).

53. Adams, R. N. Anodic oxidation pathways of aromatic hydrocarbons and amines. Acc. Chem. Res. 2, 175-180 (1969).

54. Nakamura, A., Latif, M. A., Deck, P. A., Castagnoli Jr., N. \& Tanko, J. M. Evidence for a ProtonCoupled Electron Transfer Mechanism in a Biomimetic System for Monoamine Oxidase B Catalysis. Chem. - Eur. J. 26, 823-829 (2020).

55. Costentin, C., Robert, M. \& Savéant, J.-M. Update 1 of: Electrochemical Approach to the Mechanistic Study of Proton-Coupled Electron Transfer. Chem. Rev. 110, PR1-PR40 (2010). 